\title{
RELEVANSI NILAI-NILAI TARI BEDAYA BONDHET DALAM PENDIDIKAN KARAKTER
}

\author{
TitikPutraningsih \\ FBS UniversitasNegeri Yogyakarta \\ E-mail: putraningsih29@ymail.com
}

\begin{abstract}
Abstrak
PenelitianinibertujuanuntukmendeskripsikanrelevansinilainilaipendidikanBedayaBondhetpadapendidikankarakter

di JurusanPendidikanSeniTariUniversitasNegeri

Yogyakarta.Penelitianinimenggunakanpendekatandeskriptifkualitatif, berdasarkanpada data tertulisdanlisan.SubjekpenelitianinimahasiswaJurusanPendidikanSeniTariFakultasBahasadan SeniUniversitasNegeri Yogyakarta tahun 2014.Langkah-langkahpenelitianmelaluiobservasi, pengumpulan data, wawancara, dokumentasitertulisdan non tertulis, selanjutnyadilakukananalisis data, danmenarikkesimpulan. RelevansinilainilaipendidikanpadatariBedaya Bondhetdalampembentukankarakterbudipekertiluhurmeliputi (1) Nilaipendidikansopansantun, sabar, disiplin, konsentrasi, bersemangat, percayadiri, pantangmundur, gotongroyong, bertanggungjawab, salingmenghormati, solidaritas, tenggang rasa, jujur, adil, tegas, rasa persatuandankesatuan, mendekatkandirikepada (dekatdengan) Tuhan Yang MahaKuasa.

SetelahpembelajaranBedayaBondhetdiharapkanmahasiswaadaperubahansikapdanperilakuma hasiswa yang lebihbaik.
\end{abstract}

Kata kunci: relevansi, nilai-nilai, tariBedayaBondhet, pendidikankarakter.

\section{THE RELEVANCE OF THE VALUES FOUND IN BEDAYA BONDHET DANCE IN CHARACTER EDUCATION}

\begin{abstract}
This research aims to describe the relevance of the values in BedayaBondhetdance course in terms of character education in Dance Education Department,Yogyakarta State University. This research uses descriptive qualitative approach based on written and oral data. The subject of this research is students of Dance Education Department in Faculty of Languages and Arts, year 2014. The steps of this research involve observing, data collecting, interviewing, having written and unwritten documentation, data analyzing, and concluding. The result shows that (1) the relevance of the values in BedayaBondhetdance course in terms of character educationinclude the values of politeness, patience, discipline, concentration, spirit, confidence, determination, cooperation, responsibility, respect, solidarity, consideration, honesty, justice, firmness, feeling of unity, and getting closer to God; and 2) After getting the values ofBedayaBondhet dance the students are expected to have better attitudes and behavior.
\end{abstract}

Keywords: relevance, values,BedayaBondhet dance, character education 


\section{PENDAHULUAN}

Keraton Yogyakarta sebagai pusat perkembangan tari klasik gaya Yogyakarta selalu produktif dan mengembangkan kehidupan seni tari. Pada awalnya tari sebagai bagian dari ritual kerajaan sebagai pusaka kerajaan yang dihadirkan para upacara penobatan raja. Pudjasworo menjelaskan bahwa tari klasik gaya Yogyakarta adalah hasil ekspresi budaya yang semula berkembang di tembok istana yang terdapat dalam atmosfer yang melingkupinya (Pudjasworo, 1984: 4). Artinya terciptanya tari klasik gaya Yogyakarta tidak lepas dari nilai-nilai yang terdapat di lingkungan yang melatarbelakanginya, yaitu nilai pendidikan, sopan santun, dan tata krama. Tari klasik gaya Yogyakarta mengalami perkembangan ke masyarakat, di luar tembok keraton diijinkan mempelajarinya sejak berdirinya organisasi tari dan lembaga formal pendidikan senitari KONRI/SMK I Bantul dan ASTI/ISI Yogyakarta, dan Program Studi Seni Tari IKIP Yogyakarta/UNY (Wibowo, 1981: 22-23). Bentuk tari tunggal, berpasangan, maupun kelompok baik putri maupun putera yang bersumber dari keraton Yogyakarta untuk materi kuliah Tari Jawa Klasik Yogyakarta I, II, III, di Jurusan Pendidikan Seni Tari Fakultas Bahasa dan Seni, hal ini dirasa penting bagi mahasiswa karena mempelajari tari klasik gaya Yogyakarta mengandung nilai-nilai secara umum maupun secara khusus yang bermanfaat untukmembentuk budi pekerti yang baik.

Kemajuan teknologi dan informasi semakin pesat, kondisi ini menuntut persaingan bebas menjadikan manusia berusaha memenuhi kebutuhannya sendiri tanpa menghiraukan kepentingan orang lain. Globalisasi dapat menyebabkan ajaran moral dan budaya, hal ini membahayakan bagi budaya lokal yang akan hilang tergantikan oleh budaya global. Oleh karena itu menjadi tanggung jawab seluruh masyarakat Indonesia untuk mengedepankan pendidikan dengan menggunakan budaya lokal sebagai landasan untuk menanamkan budi pekerti pada peserta didik. Dalam menanamkan nilai-nilai budi pekerti memiliki maksud dan tujuan, berusaha memberi nasehat, anjuran, materi yang mengantarkan anak didik menjadi sadar untuk berbuat baik, sehingga terbentuk watak dan kepribadian yang baik, dengan menggunakan metode ngerti, ngrasa, dan nglakoni. (http:/perpus.stainsalatiga.ac.id diunduh pada tanggal10 November 2014).Mencermati semakin lunturnya pemahaman budi pekerti dalam kehidupan keluarga, lembaga pendidikan, dan masyarakat, maka kondisi ini menjadi tanggung jawab bersama dalam pendidikan dengan pendekatan budaya agar sebuah proses pembelajaran lebih bermanfaat untuk menanamkan budu pekerti yang 
baik dalam kehidupan ini. Untuk itu pendidikan budi pekerti diusahakan selalu melekat dalam proses pembelajaran formal maupun non formal.

Pembelajaran tari klasik gaya Yogyakarta pada Jurusan Pendidikan Seni TariFakultas Bahasa dan Seni Universitas Negeri Yogyakarta meliputi teknik dan teori, maka selama belajar tari tidak sekedar melakukan gerak fisik saja, namun perlu mengetahui sejarah, bentuk, dan fungsinya serta hal-hal lain yang terkait dengan bentuk tari yang sedang dipelajarinya. Mata Kuliah Tari Jawa Klasik Gaya Yogyakarta III yang ditempuh oleh mahasiswa semester IV tahunajaran 2013-2014 mempelajaritentang bentuk tari putri kelompok yaitu tari serimpi dan bedaya. Untuk itu mahasiswa perlu diberikan pengetahuan umum tentang tari klasik gaya Yogyakarta yang diciptakan di lingkungan keraton Yogyakarta. Tari bedaya adalah komposisi tari wanita yang dibawakan oleh sembilan penari, sedangkan serimpi ditarikan oleh empat penari. Tari Bedaya diciptakan di lingkungan istana, pada upacara atau ritus kerajaan di keraton Yogyakarta menghadirkan tari bedaya sebagai alat kebesaran raja, sama dengan alat-alat kebesaran lainnya yang memiliki kekuatan magis (Hadi,2001: 83-84 ). Tari BedayaBondhetyang memiliki ciri-ciri seperti tari Bedaya pada umumnya, antara lain dalam penyajiannya dibawakan atau ditarikan oleh sembilan penari putri, penggunaan busana kostum dan tata rias yang sama, sehingga untuk membedakan peran dalam penyajiannya melalui tokoh atau peran yang dibawakan.

Budi pekerti adalah sikap dan perilaku efektif yang bersifat afektif, merupakan perwujudan etika pergaulan yang dilandasi oleh tatakrama keluhuran dan keutamaan budi pekerti. Budi pekerti mempunyai peranan dalam kehidupan, dan akan berharga bagi proses keberlangsungan hidup (Endraswara, 2006: 5-6). Menurut etika Jawa tindakan kita harus terarah pada pemeliharaan keselarasan dalam masyarakat dan alam raya sebagai nilai tertinggi. Tindakan yang betul adalah yang mendukung keselarasan, namun tindakan salah apabila tindakannya mengganggu keselarasan yang menghasilkan ketidaktenangan dan kebingungan masyarakat. Hubungan antara tindakan betul dan salah yang dipergunakan dalam etika Jawa untuk mengatur semua unsur lahir batin yaitu kategori alus dan kasar.

Pengembangan pemikiran moral perlu disertai dengan pengembangan komponen afektif, dalam aspek afektif menajamkan kepekaan hati nurani, yang memberikan dorongan untuk melakukan tindakan bermoral. Ketakwaan seseorang kepada Tuhan Yang Maha Esa, yakni ketakutan untuk melanggar larangan-Nya dan komitmen untuk melaksanakan perintah Nya, merupakan benteng yang kuat untuk mengamankan tumbuhnya pribadi yang bermoral. Manusia memiliki berbagai karakteristik, yaitu kualitas 
yang menunjukan cara-cara khusus dalam berfikir, bertindak, dan merasakan dalam berbagai situasi. Beberapa karakteristik afektif dalam proses pendidikan adalah harus melibatkan perasaan dan emosi seseorang, harus bersifat khas, harus memiliki intensitas, arah, dan target. (Zuchdi, Darmiyati, 2009: 22). Oleh karena itu dalam proses pendidikan perlunya landasan pemikiran yang berkualitas untuk melakukan pembiasaan perilaku yang baik dalam segala hal untuk kehidupan keluarga, lingkungan pendidikan, maupun di masyarakat.

Untuk mencapai tingkat pemahaman dalam belajar tari Bedaya Bondhet, baik dari sisi teori maupun praktek, maka mahasiswa perlu menambah wawasan tentang tari yang sedang dipelajarinya. Oleh karena itu selama dalam proses pembelajaran tari klasik gaya Yogyakarta, mahasiswa perlu meningkatkan apresiasi dan memahami tentang norma dalam tari klasik gaya Yogyakarta, teknik gerak yang meliputi wiraga,wirama, dan wirasa, sesuai dengan karateristik tari putri gaya Yogyakarta, sedangkan pendalaman penjiwaan penari diisi dengan Joged Mataram yang terdiri dari sawiji, greged, sengguh, dan ora mingkuh.

Selain materi sisi teknik tari, mahasiswa perlu menambah pengetahuan tentang latar belakang penciptaan tari bedaya, tujuan diciptakannya bedaya, isi dan nilai-nilai yang terkandung dalam bedaya. Bagi mahasiswa Pendidikan Seni Tari tujuan belajar tari klasik gaya Yogyakarta akan lebih bermanfaat apabila mahasiswa mampu membawakan teknik gerak tari bedaya dengan baik,dan tidak hanya sekedar menari, namun mampu memahami nilai-nilai dalam tari bedaya, sehingga diharapkan setelah belajar tari Bedaya Bondhetakan berdampak positif dalam cara berfikir, tingkah laku, berbudi pekerti, dan dapat membentuk karakter mahasiswa yang berbudi luhur. Oleh karena itu untuk membantu meningkatkan pemahaman mahasiswa tersebut, maka diperlukan sebuah penelitian tentang nilai-nilai yang terkandung dalam tari BedayaBondhet.

\section{METODE PENELITIAN}

Fenomena perilaku mahasiswa yang kurang memperhatikan perilaku sopan santun, sikap egois karena asyik bermain HP, kurang menunjukan rasa empati kepada teman karena kepentingan pribadi di lingkungan mahasiswa Jurusan Pendidikan Seni Tari. Oleh karena itu perlu dilakukan sebuah penelitian tentangrelevansi nilai-nilai tari bedaya bondhetdalam pendidikan karakter.Penelitian ini menggunakan pendekatan kulitatif untuk mendeskripsikan temuan di lapangan berdasarkan pada data tertulis dan lisan, kemudian melakukan proses deskripsi, reduksi, dan seleksi (Sugiyono, 2013: 20-21) Langkah- 
langkah penelitian dengan observasi, pengumpulan data dengan cara wawancaramendalam, dokumentasi tertulis, video, foto, selanjutnya dilakukan analisis data, triangulasi, menarik kesimpulan, dan menyusun laporan.

Tari Bedaya Bondhet sebagai materi Kuliah Tari Jawa Klasik Gaya Yogyakarta III di Jurusan Pendidikan Seni Tari Fakultas Bahasa dan Seni Universitas Negeri Yogyakarta

Data penelitian diperoleh dari sumber primer dan sumber sekunder. Sumber primer untuk memperoleh data sejarah terciptanya tari Bedaya Bondhet, bentuk penyajian, gending iringan, syair tembang, nilai-nilai dalam tari klasik keraton Yogyakarta unsur-unsur pendidikan karakter dalam pendidikan Nasional. Sumber sekunder video dan foto dari informan melalui wawancara dengan nara sumber untuk memperoleh data tentang nilainilai serat kandha dan tembang tari Bedaya Bondhet dan hal-hal lain yang terkait dengan tujuan penelitian. Tahapan pengumpulan data dimulai dengan observasi, peneliti melakukan observasi aktif (active participation) yaitu terlibat langsung sebagai pengajar pada pembelajaran tari Bedaya Bondhet, sehingga secara natural dapat mengamati perilaku mahasiswa selama pembelajaran maupun sesudah pembelajaran tari Bedaya Bondhet di Jurusan Pendidikan Seni Tari Fakultas Bahasa dan Seni untuk mengumpulkan gejala yang timbul di lapangan sehingga mendapat gambaran situasi yang akan diteliti. Observasi partisipasi aktif mengantarkan peneliti untuk secara langsung berperan serta dalam kegiatan atau aktivitas yang menjadi objek penelitian ini (Sugiyono, 2013: 227), karena peneliti sekaligus sebagai pengajar tari Bedaya Bondhet maka dari bahan ajar tari Bedaya Bondhet sekaligus untuk mengumpulkan data yang berhubungan dengan bentuk penyajian, tujuan diciptakannya tari bedaya Bondhet, sehingga dapat diketahuai pula bagaimana bentuk penyajian bedaya yang meliputi aspek gerak, iringan, pola lantai, rias dan busana, susunan gending iringan dan tembang tari Bedaya Bondhet. Wawancara dilakukan untuk mengumpulkan data tentang hal-hal yang terkait langsung maupun tidak langsung dengan tari Bedaya Bondhet. Wawancara dengan nara sumber yang mempunyai pengetahuan tentang sejarah penciptaan bedaya, tujuan pementasan bedaya, dan elemen pertunjukan tari bedaya, serta nilai-nilai yang terkandung dalam serat kandha dan tembang tari Bedaya Bondhet. Melalui wawancara mendalam diharapkan mendapatkan data yang lengkap sesuai dengan tujuan penelitian. Metode dokumentasi dilakukan dengan mengumpulkan sumber tertulis yang relevan secara langsung maupun tidak langsung dari buku-buku, jurnal, dan laporan tertulis. Informasi diperoleh pula dari foto, dokumen audio visual dan catatan iringan tari dan tembang yang membantu memperoleh informasi tentang nilai-nilai dalam tari Bedaya Bondhet. Tari Bedaya Bondhet yang asli diciptakan di masa 
pemerintahan Sultan Hamengku Buwono VII sembilan puluh menit, dokumen berupa laporan tertulis hasil penggalian mahasiswa Jurusan Pendidikan Seni Tari Fakultas Bahasa dan Seni Universitas Negeri Yogyakarta. Dokumentasi foto diperoleh saat perkuliahan dan bentuk penyajian tari Bedaya Bondhet ditata kembali yang disesuaikan dengan kebutuhan pembelajaran, maka durasi dipadatkan menjadi 30 menit. Dilakukan triangulasi bersifat penggabungan dari berbagai teknik pengumpulan data dan sumber data, peneliti mengumpulkan data dan sekaligus menguji kredibilitas data, yaitu mengecek kredibilitas data dengan berbagai teknik pengumpulan data dan berbagai sumber. Untuk mengetahui nilai-nilai pendidikan dalam serat kandha dan tembang dengan cara menggabungkan data observasi, dokumen tertulis, dan wawancara ke beberapa nara sumber kemudian dicek kembali dan membuat kesimpulan data yang sesuai dengan tujuan penelitian.Instrumen penelitian adalah peneliti, menggunakan alat bantu catatan, alat merekam suara, gambar, untuk mengumpulkan data berupa daftar pertanyaan untuk mendapatkan data yang sesuai dengan tujuan penelitian, yaitu pertanyaan tentang elemen pertunjukan tari Bedaya Bondhet dan secara umum nilai yang terkandung dalam tari bedaya, data gending dan iringan melalui studi pustaka yang bersumber pada laporan mata kuliah mandiri tari Bedaya Bondhet. Sumber data unsur pendidikan karakter dari Pusat Kurikulum Departemen Pendidikan Nasional mulai tahun 2010 menghimbau seluruh lembaga pendidikan dalam pelaksanaan pembelajaran perlu menyisipkan unsur-unsur pendidikan karakter sesuai dengan 18 butir-butir yang dikeluarkan oleh Departemen Pendidikan Nasional. Uji keabsahan data dilakukan dengan cara melakukan ferivikasi seluruh data yang telah diperoleh dengan nara sumber yang memberikan data dan isi data dilakukan pengecekan kembali. Data tersebut dipadukan dengan data yang diperoleh dari observasi yang pernah dilakukan dan dicocokan kembali dengan data primer dan data sekunder.

Analisis data dilakukan dengan cara mengorganisasikan data, menjabarkann ke dalam unit-unit, menyusun ke dalam pola, memilih yang penting, dan membuat kesimpulan. Analisis data dilakukan dari data yang diperoleh melalui wawancara, studi dokumentasi dan hasil observasi kemudian dianalisis dengan tahapan pengkategorian data, pemilihan data, telaah data, dan penarikan kesimpulan secara idiografik (keberlakuannya bersifat khusus). Analisis data pada kalimat serat kandha dan syair tembang telah dicermati dan dicek kembali dengan data pustaka dan hasil wawancara dengan nara sumber, maka dapat ditarik kesimpulan nilai-nilai yang terkandung pada serat kandha dan tembang tari Bedaya Bondhet bersifat khusus dalam pandangan etika Jawa dan berlaku di lingkungan budaya Jawa. 


\section{HASIL PENELITIAN DAN PEMBAHASAN}

\section{Nilai-nilai Umum Dalam Tari Bedaya}

Tari Bedaya adalah tari klasik gaya Yogyakarta yang berkembang di keraton Yogyakarta, kemudian berkembang di luar keraton yang dapat dipelajari di organisasi tari dan lembaga pendidikan formal di Yogyakarta. Sistem nilai budaya Jawa bahwa dalam masyarakat Jawa pengakuan dirinya sama se-sama-nya, maka menjadi kaidah bersama dalam tata cara kehidupan adalah kelompok/masyarakat. Pendapat masyarakat tampak pada ketentuan adat, tradisi, dan kehidupan sehari-hari, seperti halnya pentingnya memahami nilai-nilai etika moral, estetika, sosial, dan nilai religius. Tari keraton Yogyakarta mempunyai nilai etik, estetika, sosial, dan nilai religius (Sunaryadi, 2012: 5-11) yang diuraikan sebagai berikut:

a. Nilai Religius yang terkandung dalam tari keraton Yogyakarta karena pada awalnya tari merupakan karya seni yang disakralkan di dalamnya terkandung falsafah kehidupan. Bedaya ditarikan oleh sembilan penari puteri yang menggambarkan wujud tubuh manusia yang saling berhubungan dan menjadi kesatuan. Ketika seseorang berkeingingan meraih sesuatu dengan cara bersemedi/ bermeditasi, mendekatkan diri dengan Tuhan, maka ia harus pati rasa (memusatkan pikiran kepada Tuhan)

b. Nilai Etik, dalam budaya Jawa dikaitkan dengan baik dan buruk, hubungan antara baik dan buruk dapat dilampaui dengan cara peningkatan kesadaran, hal itu dikenal dengan kematangan jiwa manusia. Tingkat kedewasaan akan membentuk watak karakter yang menentukan perilaku atau moral seseorang, bagaimana seseorang harus hidup menjadi manusia yang baik.

c. Nilai sosial pada pendidikan karakter manusia Jawa mengutamakan kesatuan antara sesamanya. Kesadaran bahwa dirinya merupakan bagian dari sesamanya, yang menuntut manusia menciptakan rasa yang membuat nyaman orang lain. Persatuan dalam sebuah kelompok atau masyarakat dapat digalang melalui nilai rukun, tenggang rasa, toleransi, dan gotong royong.

d. Nilai estetika tampak pada kekuatan estetika tari Jawa terletak pada rasa, dalam tari yang berasal dari keraton adalah sebagai motor penggerak untuk mengekspresikan karakter yang dibawakan. Nilai Estetika tari merupakan merupakan refleksi dari pengendalian diri, karena segala sesuatu dibuat untuk individu maupun kelompok. Estetika tari keraton dapat dilihat dari gerak, tata rias, dan busananya.Pola lantai secara umum dalam tari bedaya dibawakan oleh sembilan penari yang mempunyai peran 
sebagai Endhel Pajek, Batak, Jangga, Dadha, Buntil, Apit Ngajeng, Apit Wingking, Endhel Wedalan Ngajeng, Endhel Wedalan Wingking. Tari Bedaya menggunakan pola lantai yang sama yaitu rakit lajur, rakit ajeng-ajengan, mlebet lajur, medal lajur, rakit tiga-tiga, dan rakit gelar dan masing-masing bentuk pola lantai mempunyai makna dan simbol (Murdiyati, 2009: 90-95).

Untuk mencapai tingkat pemahaman dalam belajar tari Bedaya Bondhet, baik dari sisi teori maupun praktek, maka mahasiswa perlu menambah wawasan tentang tari yang sedang dipelajarinya baik secara teknik dari aspek pendukung tari maupun nilai yang terkandung dalam tari Bedaya yang sedang dipelajari.

\section{Nilai-nilai Khusus Dalam Tari Bedaya Bondhet}

Sistem nilai budaya Jawa bahwa masyarakat Jawa pengakuan bahwa dirinya sama se-sama-nya, maka menjadi kaidah bersama dalam tata cara kehidupan adalah kelompok/masyarakat. Pendapat masyarakat tampak pada ketentuan adat, tradisi, dan kehidupan sehari-hari, seperti halnya pentingnya memahami nilai-nilai etika moral, estetika, sosial, dan nilai religius (Sunaryadi, 2012: 5-11). Dalam proses belajar tari Bedaya Bondhet mahasiswa mempunyai kemampuan belajar yang dapat diartikan sebagai kemampuan untuk melakukan perubahan melalui sebuah proses yang telah dirancang sebelumnya. Agar hasil belajar dapat mencapai nilai optimal, maka sebagai sebuah proses untuk mengubah tingkah laku harus melalui latihan dan pengalaman langsung. Oleh karena itu mahasiswa perlu memahami tentang nilai-nilai yang terkandung dalam tari Bedaya Bondhet, agar dapat mengambil manfaat positif dalam nilai-nilai tersebut dalam pembentukan karakter dan budi pekerti yang luhur, sehingga dapat melakukan pembiasaan perilaku dan moral yang baik.

Tari bedaya secara umum dibawakan oleh sembilan penari putri, walaupun ada tari bedaya yang lain ditarikan oleh enam atau tujuh penari. Tari Bedaya Bondhet diciptakan pada masa Sultan Hamengku Buwono VII yang diringi gending Bondhet. Kata bondhet mempunyai arti nggubel, godlelan (Poerwadarminta, 1943: 10) dan mendekat terus kepada, bondhet mengandung suatu pesan yang berguna (Bale Poestaka, 2003: 50). Setelah mencermati arti kata bondhet tersebut dapat diketahui bahwa tari Bedaya Bondhet, mengandung pesan agar manusia selalu mendekatkan diri kepada Tuhan dengan menjalankan perintahNya dan menjauhkan laranganNya. Nilai pendidikan Ketuhanan yang bermanfaat bagi manusia di dunia ini selalu mendekatkan diri dengan Tuhan dengan cara bersyukur, memohon ampun dan bertobat atas kekhilafan manusia. 
Tari bedaya Bondhet dipentaskan dalam acara ritual jumenengan Sultan Hamengku Buwono VII , isi ceritera menggambarkan sifat dan karakter Sultan Hamengku Buwono VII. Tari bedaya secara umum mengandung nilai-nilai positif dalam simbol gerak, iringan, tembang, pola lantai, rias, dan busana. Sifat dan karakter Sultan Hamengku Buwono VII yang tersirat dalam cerita tari Bedaya Bondhetbisa menjadi tauladan untuk membentuk budi pekerti manusia dalam kehidupan sehari-hari. (Lestari, 1997: 10). Nilainilai yang terkandung dalam Bedaya Bondhet apabila dicermati bermanfaat bagi penari, pengrawit, penonton, dan masyarakat pada umumnya. Berikut ini akan diuraikan secara khusus tentang nilai pendidikan dalam kandha dan tembang Tari Bedaya Bondhet.

\section{Nilai Pendidikan SeratKandha dan Tembang Dalam Tari Bedaya Bondhet}

Pendidikan karakter untuk membentuk perilaku dan moral manusia dijelaskan oleh Suyanto dalam sembilan pilar karakter, pendidikan karakter adalah pendidikan budi pekerti plus, artinya melihat aspek pengetahuan, perasaan, dan tindakan. Sembilan pilar karakter yang berasal dari nilai-nilai luhur universal yaitu: 1) Karakter cinta Tuhan dan segenap ciptaan-Nya 2) Kemandirian dan tanggung jawab 3) Kejujuran, amanah, diplomatis 4) Hormat dan santun 5) Dermawan, suka menolong, gotong royong/kerjasama 6) Percaya diri dan pekerja keras 7) Kepemimpinan dan keadilan 8) Baik dan rendah hati 9) Toleransi,kedamaian dan kesatuan (Suyanto, 2009). Di bawah ini akan diuraikan secara terperinci tentang nilai pendidikan yang terkandung dalam serat kandha dan tembang tari Bedaya Bondhet sebagai berikut:

\section{a. Serat Kandha}

Sesetbyar wauta, anenggih ingkang kawiyosaken punika, kalangenandalem Bedhaya, yasandalem Ingkang Sinuwun Sultan Hamengku Buwa$n a$, ingkang jumeneng kaping : VII: ing nagari Ngayogyakarta Hadiningrat.

Karsadalem amarsudyeng karsa, angresakaken yasa Pasindhen Bedhaya amunduhut cariyosipun kagungandalem Serat Babat, nalikanira Raden Daniswara, kentas saking nagari ing Medhangkamulan. Kaendhih dening Sang Prabu Ajisaka.

Marang ing tyas enget kusuma rembesing madu, wijiling amara-tapa, trahing andana warih, risaksana lejar amangun tapa aneng salebeting Guwa Terusan, kaprenah ing Wiwara-jana. muja semedi angeningken pancadriya, aneges karsaning kang Murweng Pandum. Yen tan antuk sihing Jawata, suka lila binajuta ing Dewa kang linuwih.

Ing ngriku praptaning nugraha, marga tekaping rencana, Widadari kang sapta, samya mrih wudharing kang sutapa, ing tyasnya Radyan datan paja yen kagiwanga. 
Wondene sasaniskaranira, sampun kocap wonten kagungandalem Serat pasindhen sadaya.

Wauta, sareng sami munggeng ing sasana-taya, dhasar sami endahing kang warna, rinenggeng ing busana, Yen sinawang saking mandrawa, lir mulat teka bebondhetan sesampurira.

Inti cerita yang digambarkan dalam Tari Bedaya Bondhet dapat diketahui melalui Serat Kandha yang isinya menceriterakan tari Bedaya Bondhet diciptakan pada masa Sri Sultan HB VII pada tahun 1877, mengambil ceritera dari Serat Babad Medang Kamulan (230-999) yang menceriterakan Prabu Daniswara sedang bertapa di Gua Terusan. Maksud penciptaan bedaya Bondhet untuk menggambarkan figur dari Sri Sultan HB VII, yang mempunyai kepribadian yang baik dan bertekad ingin menyatukan tanah Jawa (Lestari, dkk., 1996: 6-7). Setelah berdoa melalui bertapa (meditasi) maka dapat menyatukan tanah Jawa. Melalui uraian pada Serat Kandha bisa diketahui maksud dan isi cerita tari yang ditampilkan. Nilai pendidikan yang terkandung dalam ceritera tersebut bahwa manusia apabila ingin mencapai cita-cita akan bisa tercapai dengan bekerja keras, tidak putus asa, dan berdoa dengan mendekatkan diri dengan Tuhan Yang Maha Kuasa.

\section{b. Bawa Sekar Ageng: Candra Menggeng}

Wus kalebeng cetha,

Raden Daniswara,

Ing Medhangkamulan,

Nedya mangun tapa,

Neng Guwa Terusan,

Antuk sih nugraha,

Lumunturing Dewa,

Lir bondhet swaranya.

Syair tembang tersebut di atas dicermati mengandung nilai pendidikan manusia mendekatkan diri dengan Tuhan Yang Maha Kuasa, rasa persatuan dan kesatuan, sopan santun, sabar, disiplin, konsentrasi, bersemangat, percaya diri, pantang mundur, bertanggung jawab, dan jujur.

\section{c. Gending Bondhet Laras Pelog Pathet Nem}

DHAWAH

Babo,Kacarita, Antuk, Tigang candra,

Engge,Tanantara, Cobaning Hyang, KangMisesa,

Babo,Praptanira, Wida darisapta,

Engge, Mangrencana, Marang ingkang, Matiraga,

Babo,Kawarnaha, RadyanDaniswara, 
Engge,Datan samar, Tandya angeningken cipta,

Ba bo,AmateniPanca driyanira,

Engge, Asidhakep,Netralir nen-dra niskara,

Engge.

Syair tembang di atas dicermati mengandung nilai sopan santun, tata krama, unggah ungguh, sabar disiplin, konsentrasi, bersemangat, percaya diri, pantang mundur, gotong royong, bertanggung jawab, saling menghormati, solidaritas, tenggang rasa, jujur, adil, tegas, rasa persatuan dan kesatuan, mendekatkan diri kepada (dekat dengan) Tuhan Yang Maha Kuasa.

\section{d. Minggah Ladrang Prabudewa}

Babo

Henis ka wuryaning hangga,

Risang wus raga Bathara,

Jumbuh maring cipta,

Babo

Wus jumeneng Prabanira,

Ngayunken paningal,

Nglangut saparane.

Babo

Hening gaibing jawata,

Padhang terawangan,

Alok alok hose,

Engge.

Babo

Tan samar pamor ing suksma,

Nglangut napas wus murcita,

Raga tanpa daya.

Babo

Datan dangu praptanira,

Waranggana sapta,

Sumedya ngrencana;

Babo

Pinajupat lampahira,

Sarwi amiraga,

Alok alok hose,

Engge

Babo

Samya endah warnanira,

Wimbuh angadi busana,

Ganda arum ngambar.

Babo

Sira risang sekaringrat,

Dewi Mayangkara,

Hiwah Widyasmara.

Babo

Sang kusuma Cadrasmara, 
Lan Ganda asmara,

Alok alok hose

Engge.

Babo

Samya lumebet ing guw,

Nyakei sang maratapa,

Matur manuara.

Babo

Nor raga memelas driya,

Mesem angujiwat,

Tan keguh sang Tapa.

Babo

Para Widadari sapta,

Nulya ngleksanani,

Denira ngrencana.

Syair tembang tersebut di atas dicermati mengandung nilai mendekatkan diri dengan

Tuhan Yang Maha Kuasa, rasa persatuan dan kesatuan, sopan santun, tata krama, unggah ungguh, sabar, disiplin, konsentrasi, bersemangat, percaya diri, pantang mundur, bertanggung jawab, jujur, tegas, saling menghormati, solidaritas, tenggang rasa, gotong royong.

\section{e. Gending Ketawang Langen Gita}

KathahSolahe para Hapsari

Alelendheh,Tanapi angayang ayang,

Rebat karya,Miraga mawarna warna.

Nenggih,Sang Daniwara tan keguh,

Mring panggodha, tadyan para Waranggana.

Samya ngetog, Kridaning pangrencananya.

Meksa,Datan kagiwanging driya,

Pra Hapsari, Nulya mundur palarasan.

Mangayangan, Panggodhane tanpa karya.

Gantya, Warnanen kang aneng guwa,

Sawusira,Lengser para waranggana,

Arsa mudhar,Denir manungkup uja.

Yata, Wau Sang Prabu Sindula,

Nata Debya,Kang wus sarira Bathara.

Datan Samar,Mring sedyne Daniswara.

Nulya,Mrepeki sarwi manabda,

Putuningsun,Musthikaning Jagadraya.

Denira amangun tapa.

Sira, Sinung garwa waranggana,

Pra Hapsari Tutungguling Swargaloka.

Benjing tembe,Linuri Rat Tanah Jawa.

Kathah,Piwulange mring kang wayah,

Agal aIus, Kagunan myang kasantikan,

Wus kacakup,Sang Sindula nulya musna. 
Tandya, Widadari catur prapta,

Wus ginarwa, Marang Radyan Daniswara.

Langkung trustha,Nulya ngempalaken wadya.

Mangkya,Harsa angrebaseng yuda,

Males ukum,Marang Prabu Ajisaka.

Titi brastha,Tan cinatur yudanira.

Syair tembang tersebut di atas dicermati mengandung nilai pendidikan mendekatkan dengan Tuhan Yang Maha Kuasa, rasa persatuan dan kesatuan, sopan santun, sabar, disiplin, konsentrasi, bersemangat, percaya diri, pantang mundur, bertanggung jawab, jujur, tegas, sopan santun/tata krama/unggah ungguh, sabar disiplin, konsentrasi, bersemangat, percaya diri, pantang mundur, gotong royong, bertanggung jawab, saling menghormati, solidaritas, tenggang rasa, jujur, adil, tegas, rasa persatuan dan kesatuan, mendekatkan diri kepada (dekat dengan) Tuhan Yang Maha Kuasa.

\section{Relevansi Nilai Pendidikan Tari Bedaya BondhetDalam Pendidikan Karakter}

Mulai tahun ajaran 2011, seluruh tingkat pendidikan di Indonesia menyisipkan pendidikan berkarakter yang berupa 18 nilai-nilai pengembangan pendidikan budaya dan karakter bangsa yang dibuat oleh Diknas dalam proses pendidikannya, untuk itu dalam proses pembelajaran saling bersinergi antara materi, dosen, dan mahasiswa mereliasasikan unsur-unsur pendidikan yang tercermin dalam nilai-nilai pendidikan karakter (sumber Pusat Kurikulum Departemen Pendidikan Nasional, 2010) yaitu:Religius, Jujur, Toleransi, Disiplin, Kerja keras, Kreatif, Mandiri, Demokratis, Rasa ingin tahu, Semangat Kebangsaa, Cinta Tanah Air, Menghargai Prestasi, Bersahabat, Komunikatif, Cinta Damai, Gemar Membaca, Peduli Lingkungan, Peduli Sosial, Tanggung Jawab

Oleh karena itu melalui pembelajaran tari Bedaya Bondhetyang mengandung nilai-nilai pendidikan diharapkan mampu membentuk budi pekerti yang lebih baik dari sikap mahasiswa sebelumnya. Mahasiswa diharapkan dapat merubah dirinya yang lebih baik misalnya tentang sopan santun, kemudian menjadi mengerti perilaku dan sikap yang baik sesuai dengan etika dan sopan santun. Dalam proses pembelajaran ini diajarakan pula nilai kesadaran selalu mendekatan diri dengan Tuhan Yang Maha Kuasa,secara simbolis pada gerak sembahan baik di awal tari maupun pada saat berakhirnya tari.

Setelah dilakukan wawancara dengan mahasiswa peserta kuliah dan hasil angket yang kemudian dilakukan analisis deskriptif, maka dapat diketahui nilai-nilai 
pendidikan yang bermanfaat untuk membentuk karakter dan kepribadian mahasiswa, diuraikan sebagai berikut:

1. Gerak tari Bedaya mempunyai karakter tari putri klasik gaya Yogyakarta dibawakan dengan irama pelan dan halus, hal ini mencerminkan perilaku karakter puteri Jawa yang halus tingkah laku dan berbudi pekerti yang baik. Melalui pengalaman melakukan gerak yang mempunyai karakter gerak lembah lembut dengan irama pelan, hal itu menjadikan mahasiswa lebih bisa mengontrol diri dan bertindak lebih sabar di dalam perilaku maupun menghadapi segala masalah yang dihadapi.

2. Karakter tari putri gaya Yogyakarta tampak pada dinamika di dalam batinuntuk membawakan tari Bedaya Bondhet tampak halus dan bersemangat, walaupun pembawaan gerak lebih halus dari pada karakter tari putera. Jika pembawaan tari ini dilakukan dengan sikap malas-malasan tentunya penari akan tampak lemah dan tidak mengekspresikan tari yang sedang dibawakan. Nilai semangat yang bermanfaat untuk melakukan segala aktifitas dilakukan dengan kesadaran dan dorongan semangat dan tidak lemah atau malas dari diri manusia sendiri.

3. Kedisiplinan mahasiswa semakin meningkat karena di dalam menarikan tari ini dituntut mentaati norma dalam tari klasik gaya Yogyakarta yang terdiri dari wiraga, wirama, dan wirasa, yaitu melakukan gerak dengan teknik yang benar, mengikuti irama gerak sesuai irama gending yang mengiringi, dan mengekspresikan gerak sesuai dengan peran (karakter yang dibawakan). Hal ini menunjukan keunikan yang berbeda dengan gaya tari daerah lain. Nilai kedisiplinan dapat diterapkan oleh mahasiswa di dalam mengikuti pembelajaran untuk datang tepat waktu, mengerjakan tugas-tugas yang diberikan dosen, sehingga perilaku mahasiswa terlatih melakukan pembiasaan untuk disiplin.

4. Konsentrasi total perlu dilakukan penari selama membawakan tari, karena jika tidak dilakukan dengan penuh konsentrasi tentunya jiwa di dalam menari tidak akan muncul. Untuk mengekspresikan tari ini perlu penjiwaan yang kuat dengan cara berkonsentrasi. Hal ini tercemin pada saat mengikuti pembelajaran tari Bedaya Bondhet perlu konsentrasi agar mencapai hasil yang optimal, mahasiswa tidak akan melakukan aktifitas lain yang mengganggu misalnya berbicara dengan temannya atau bermain HP pada saat dosen menjelaskan.

5. Menanamkan sikap percaya diri sesuai peran masing-masing dari sembilan penari yang membawakan tari bedaya ini, karena penari harus bisa membawakan peran tanpa terpengaruh dari peran penari yang lain sesuai dengan posisinya, sehingga 
dapat terjalian kesatuan yang utuh untuk membawakan tari bedaya sesuai dengan fungsi masing-masing peran (Endhel Pajek, Batak, Jangga, Dadha, Buntil, Apit Ngajeng, Apit Wingking, Endhel Wedalan Ngajeng, Endhel Wedalan Wingking). Sikap percaya diri dalam membawakan tari secara tidak langsung menanamkan nilai percaya diri dalam menentukan langkah kehidupan ini sesuai dengan cita-cita yang diinginkan.

6. Jiwa semangat pantang mundursemakin meningkat untuk menempuh kuliah, karena termotivasi tumbuh keinginan untuk belajar tuntas dan mencapai hasil yang optimal.

7. Sikap dan perilaku gotong royong antar mahasiswa semakin meningkat karena mahasiswa dituntut untuk tidak egois di dalam kebersamaan melakukan gerak maupun membentuk pola lantai. Tari Bedaya Bondhetini merupakan tarian kelompok sehingga membutuhkan kerjasama yang solid.

8. Menanamkan sikap mahasiswa yang bertanggungjawab, karena mahasiswa dituntut bertanggungjawab atas tari yang akan dibawakan dari awal sampai akhir, menghafal posisi pola lantai, melakukan teknik gerak sesuai dengan norma yang berlaku, membawakan sesuai dengan perannya, sehingga secara tidak langsung menanamkan pembiasaan rasa tanggung jawab mahasiswa setiap perbuatan atau aktifitas dalam kehidupan.

9. Nilai kesadaran selalu mendekatkan diri dengan Tuhan Yang Maha Kuasa,dengan melakukan gerak sembahan baik di awal tari maupun pada saat berakhirnya tari ini. Hal itu menanamkan kepada diri mahasiswa sebelum memulai setiap aktifitas perlu dilandasi doa kepada Tuhan Sang Pencipta agar manusia selalu dalam lindunganNya dan harapan permohonan manusia akan dikabulkanNya. Hal ini merupakan simbol hubungan kawula gusti yang tak terpisahkan hubungan manusia dengan Tuhan.

10. Pembelajaran tari kelompok ini menanamkan rasa dan sikap tolong menolong sesama teman, membentuk pribadi menjadi lebih solid saling merangkul antar teman dalam proses belajar tari Bedaya Bondhet. Bagi mahasiswayang sudah bisa membantu yang belum bisa untuk bersama belajar kelompok secara mandiri, tanpa ada unsur terpaksa. Sikap tolong menolong ini tercemin pada mahasiswa yang ingin secara bersama-sama dalam satu kelas untuk mencapai nilai yang optimal.

11. Tidak sombong, rendah hati, dalam berinteraksi dengan sembilan penari merupakan satu kesatuan dalam membawakan tari Bedaya Bondhet. 
12. Belajar mengontrol emosi melalui ekspresi wajah yang terpancar dari dalam (kesungguhan hati dalam membawakan tari) tidak diijinkan tersenyum lebar dengan menarik garis tawa.

Setelah mahasiswa mengikuti pembelajaran tari Bedaya Bondhet diharapkan akan mengalami perubahan yang lebih baik tentang pemahaman dan perilaku positif. Memahami untuk meraih kesuksesan dalam belajar hendaknya dengan bekerja keras dan tidak putus asa, percaya diri, jujur, dan gotong royong sesama teman baik di kelas selama belajar tari Bedaya Bondhet maupun di luar kelas (kehidupan sehari-hari). Usaha yang dilakukan harus disertai dengan doa dan selalu mendekatkan diri kepada Tuhan Yang Maha Kuasa.

\section{KESIMPULAN}

Hasil penelitian menunjukan bahwa pembelajaran tari klasik gaya Yogyakarta secara umum mengandung nilai etik (filsafat moral), estetika, religius, dan sosial. Tari Bedaya mengandung nilai estetika secara umum pada simbol gerak, gending iringan, dan pola lantai yaitu, rakit lajur, rakit ajeng-ajengan, rakit medal lajur, rakit mlebet lajur, rakit gelar, rakit tiga-tiga. Nilai secara khusus pada gending iringan dan tembang tari Bedaya Bondhet mengandung nilai pendidikan cinta Tuhan.

Relevansi nilai-nilai pendidikan pada tari Bedaya Bondhet pada mahasiswa Jurusan Pendidikan Seni Tari Fakultas Bahasa dan Seni Universitas Negeri Yogyakarta dalam pembentukan karakter berbudi pekerti luhur meliputi (1) Nilai pendidikan sopan santun, sabar, disiplin, konsentrasi, bersemangat, percaya diri, pantang mundur, gotong royong, bertanggung jawab, saling menghormati, solidaritas, tenggang rasa, jujur, adil, tegas, rasa persatuan dan kesatuan, mendekatkan diri kepada Tuhan Yang Maha Kuasa. (2)Setelah pembelajaran tari Bedaya Bondhet diharapkan ada perubahan sikap dan perilaku mahasiswa yang lebih baik. Pengembangan pemikiran moral perlu disertai dengan pengembangan komponen afektif, dalam aspek afektif menajamkan kepekaan hati nurani, yang memberikan dorongan untuk melakukan tindakan bermoral. Ketakwaan seseorang kepada Tuhan Yang Maha Esa, yakni ketakutan untuk melanggar larangan-Nya dan komitmen untuk melaksanakan perintahNya, merupakan benteng yang kuat untuk mengamankan tumbuhnya pribadi yang bermoral. 


\section{DAFTAR PUSTAKA}

Departemen Pendidikan dan Kebudayaan: Pusat Penelitian Sejarah dan Budaya, Proyek Penelitian dan Pencatatan Kebudayaan Daerah, 1977.Sejarah Daerah Istimewa Yogyakarta.

Dewan Ahli Yayasan Siswa Among Beksa Ngayogyakarta Hadiningrat, 1981. Kawruh Joged Mataram. Yogyakarta: Dewan Ahli Yayasan Siswa Among Beksa Ngayogyakarta Hadiningrat

Fuji Astuti, 2013. Penerapan Pendidikan Karakter Melalui Pembelajaran Tari pada PAUD. IMAJI Jurnal Seni dan Pendidikan. Vol. 11. No. 1, Februari 2013.

Hadi, Sumandiyo, 2001. Pasang Surut Tari Klasik Gaya Yogyakarta. PembentukanPerkembangan-Mobilitas. Yogyakarta: Lembaga Penelitian Institut Seni Indonesia Yogyakarta.

Lindsay, Jennifer. 1991. Klasik Kitsch Kontemporer Sebuah Studi Tentang Seni Pertunjukan Jawa. Yogyakarta: Gadjah Mada University Press.

Lestari, Anik Dwi, dkk., 1996. “Tari Bedaya Bondhet”. LaporanHasil Penggalian. Program Studi Pendidikan Seni Tari Fakultas Bahasa dan Seni Universitas Negeri Yogyakarta.

Endraswara, Suwardi, 2003. Metode Penelitian Kebudayaan. Yogyakarta: Gadjah Mada University Press. , 2006. Budi Pekerti Jawa Tuntunan Luhur dari Budaya Adiluhung.Yogyakarta: Buana Pustaka.

Masunah, Juju dan Tati Narawati, 2003. Seni dan Pendidikan. Bandung: Remaja Rosdakarya

Murdiyati, Y, 2009. Bedhaya Purnama Jati Karya KRT. Sasmintadipura: Ekspresi Seni Jagad Tari Keraton Yogyakarta. Yogyakarta: Cipta Media.

Muslich, Masnur. 2010.Pendidikan Karakter : Menjawab Tantangan Krisis Multidimensional.Malang: Bumi Aksara

Polak, Mayor, 1979. Sosiologi Suatu Pengantar Ringkas. Jakarta: PT Ichtiar baru.

Pudjasworo, Bambang, 1982. "Studi Analisa Konsep Estetis-Koreografis Tari Bedaya Lambangsari". Penelitian yang diajukan kepada Panitya Ujian Akademi Seni Tari Indonesia di Yogyakarta sebagai salah satu syarat untuk Ujian Seniman Tari. Yogyakarta: Akademi Seni Tari Indonesia. 
Sunaryadi, 2012. "Nilai-Nilai Tari Keraton Yogyakarta Relevansinya bagi Penanaman Karakter Bangsa". Makalah dalam rangka Ujian Terbuka untuk meraih gelar Doktor di Universitas Gadjah Mada, 2014.

, 2013. Filsafat Seni. Suatu Tinjauan dari Perspektif Nilai Jawa. Yogyakarta: Lintang Pustaka Utama

Sugiyono, 2013. Metode Penelitian Kuantitatif, Kualitatif, dan $R \& D$. Bandung: Penerbit Alfabeta.

Suseno, Franz Magnis, 1985. Etika Jawa. Sebuah Analisa Falsafi tentang Kebijaksanaan Hidup Jawa. Jakarta: PT. Gramedia.

UNY, 2011. Bunga Rampai, Pendidikan Karakter dalam Perspektif Teori dan Praktek.Yogyakarta: UNY Pres.

Wibowo, Fred, dkk., 1981. Mengenal Tari Klasik Gaya Yogyakarta. Yogyakarta: Dewan Kesenian Yogyakarta.

Zuchdi Darmiyati, 2008. Humanisasi Pendidikan: "Menemukan Kembali Pendidikan yang Manusiawi”. Jakarta, PT. Bumi Aksara.

http/www.mandikdasman.depdiknas.go.id/web/pages/urgensi.html.Urgensi Pendidikan Karakter. Suyanto, 2009. Diunduh pada tanggal 20 Maret 2014

http/www.puskur.net/file/1 Pendidikan budaya dan karakter bangsa.Pelatihan Penguatan Metodologi Pembelajaran Berdasarkan Nilai-nilai Budaya untuk Membentuk Daya Saing dan Karakter Bangsa, oleh Pusat Kurikulum Departemen Pendidikan Nasional, 2010. Diunduh pada tanggal 27 Oktober 2014.

http/perpus.stainsalatiga.ac.id

Pemikiran Ki Hajar Dewantara Tentang Konsep Budi Pekerti. Diunduh pada tanggal 10 November 2014. 